\title{
Neo-Structuralism and the Contestation of Sacred Place in Biblical Israel
}

\author{
SETH D. KUNIN
}

Durham University

\begin{abstract}
One of the most interesting features of anthropological discussions (and those in related disciplines) of sacred place has been the issue of contestation both in relation to the construction of sacred place and in the construction of theorizing about such spaces. ${ }^{1}$ This aspect, however, has often been ignored or underplayed in structuralist or structural-functionalist analyses (as for example in many of Victor Turner's discussions of pilgrimage). This is also in part true of my earlier structuralist analysis of this subject, God's Place in the World (1998). That volume examined a range of different models of sacred space found in Judaism from the Biblical to the modern period. While the discussion of Biblical use of sacred space did touch on alternative models of space (centralized and decentralized models), the issues of contestation and a theoretical basis for a more complex understanding of structure were not developed.
\end{abstract}

This article takes up these issues. It suggests that the apparent monolithic voice of much of the Biblical text reflects an imposition of a particular ideological stance that leads to the emphasis on a particular variation of the underlying structural model. Thus we find a strong emphasis on the centralized model, which finds its classical exemplification in the Temple in Jerusalem - a model that is closely implicated in the power structure of

\footnotetext{
${ }^{1}$ See for example the discussion of the development of these issues in Sheldrake (2001, 4-22). See also Friedland and Hecht (1991, 24-28) for a discussion of the multivalent nature of sacred place. The issue of conflict is specifically taken up in Eade and Sallnow's (1990) discussion of the contested nature of Christian pilgrimage in which they particularly challenge Turner's concept of communitas as the significant outcome of pilgrimage. One of the aspects of contestation that is developed below relates to the work of Lefebvre (1991). This is specifically seen in the discussion of the dominant narrative of space, which reflects minimally the imposition of a dominant ideology and maximally a narrative of repression in relation to both alternative Israelite models and perhaps in regard to the Canaanites among whom the Israelites lived and from whom they most likely emerged.
} 
post exilic Israel. Although this ideological stance is the most strongly developed, there are a significant number of texts that develop variants on the underlying structural model. The presence of these variants suggests that use of both place and structure were not uncontested in Israelite culture, thus the monolithic presentation needs to be modified in respect of this contestation, and be understood as an artifact of a particular historically contextualized ideological system.

One of the interesting aspects highlighted by the discussion of Israelite structure/s below is that the differing models of sacred space developed are not based on different underlying structures; rather they are variants on the same underlying structures with the variations arising from differential emphasis or de-emphasis on aspects of the underlying structural equation. The issues raised require a rethinking of some aspects of the structuralist understanding (or depiction) of culture. The ethnography particularly challenges structuralism's monolithic depiction and abstraction of culture and the role of ideology in the shaping and privileging of underlying structural models. This article initially takes up the theoretical questions, to provide a basis for the understanding of the particular ethnography. It then develops the details of the ethnography to both illustrate and illuminate the theoretical points. The article concludes with a brief discussion of the implications for structuralism and the understanding of culture on a broader level.

Although, due to issues of space, we will not go into detail about the more general aspects of the structuralist or more precisely neo-structuralist theoretical approach and methodology that underlie the discussion, a more detailed discussion can be found in a recent publication, We Think What We Eat (Kunin 2004), nonetheless it is appropriate to highlight some of the differences with classical structuralism. One of the key theoretical moves is from the general to the particular, and in the context of this paper to even the more particular. Structuralism tended to, or perhaps in principle claimed to, look for abstract equations that underlie all cultural forms. Neostructuralism particularizes this search, seeking culture-specific underlying structural equations. This is related to a significant theoretical move - clas- 
sical structuralism sought an abstract underlying structure, neo-structuralism seeks an abstract underlying structuring principle or process. Both of these abstractions are aspects of how we think, one theorizes a common structure the other a common structuring process. As discussed below, the ethnographic material suggested here as well as a much broader range of ethnography suggest that some aspects of this particularizing process may need to break down the notion of culture and see variant structural forms (as opposed to process) as being found not only at the level of different cultures, but also within those cultural formations.

A second significant development in neo-structuralism is the emphasis on transformation. Traditional structuralism was often seen as presenting a static view of culture, presenting a problem in relation to the ethnographic evidence of diachronic transformation in cultural formations. Neo-structuralism attempts to grapple with transformation on a number of different levels. First, where possible the analysis examines different layers of text, particularly from distinct diachronic contexts. This form of analysis allows for a detailed depiction of the process of transformation at work. It provides a basis for determining the level of transformation, that is, whether it is privileging or de-privileging preexisting structural elements or indeed if it is a more significant transformation of structural elements.

Second, it provides a basis for understanding the processes of transformation, particularly through the recognition of the complexity of culture and the discussion of forms of agency that arise in relation to the complex interaction of individual identity and culture. Structuralism has tended to depict culture and its related underlying structure as essentially unitary - with one uncontested structure defining a particular cultural formation. Communities, however, are made up of competing interest groups, ideological systems and power structures which may understand and define themselves in different ways - thus, in line with the change in understanding of Israelite culture, there needs to be a move away from the monolithic understanding and depiction of both culture and underlying structure. This change is in line with much recent anthropological discussion, which challenges the 
concept of culture both as a construct of the ethnographer or as an artifact of a particular ideological system.

On the structural level this view has an important implication: if culture is not unitary can underlying structure be seen as unitary? Neo-structuralism suggests that underlying structure must be characterized simultaneously by both unity and multiplicity. On the one hand, there needs to be a degree of structural identity; this identity provides the basis for a common framework of meaning and understanding. When this identity is not present or is significantly weakened, structural and cultural fragmentation can occur. It is this loss of identity that is seen in the ultimate division between rabbinical Judaism and Christianity. On the other hand, due to the complex nature of "cultures", different groups may use (unconsciously) underlying structural forms in different ways. They may privilege or de-privilege different structural elements, or they may emphasize or deemphasize different aspects of the underlying structural equation. While the element of structural identity plays a conservative role in culture, the structural complexity can be a motor for change. As different interest groups push the boundaries of underlying structural possibility, there is always the possibility that they may break through the boundaries and move the process of transformation from one of emphasis to a significant change in structural form. This type of transformation may be related to the relative power of different interest groups, and to "revolutionary" changes in control of the productive features of society.

This view also sees the notion of culture as an identifiable and bounded unit as being problematic. The boundaries of a particular culture often arise in the minds of ethnographers of external political or colonial agencies. In many cases the boundaries between different communities in terms of how they live, think and interact with the world is much fuzzier. Even if such boundaries are internally determined on the basis of some ideological position, as we see in the Israelite material, the actual distinctiveness of a particular community's practices is often an artifact of the ideology rather than the ethnographic "reality". 
While this understanding of culture creates certain problems for the ethnographer, it also provides a basis for understanding the process of structural transformation. Like the internal complexity highlighted above, the fuzzy nature of boundaries between different "cultural" forms provides an additional set of transformational possibilities; the fuzzy edges would allow for variations on structure, which might include significant cultural transformations. As a community develops over time, with different groups shaping ideological systems, these variations would provide the material for potentially significant structural transformation. This, however, should not be overstated. Cultural systems often maintain means for minimizing the power of peripheral elements. This is seen in the Israelite system in the association of the Temple and palace: that is, religious and political authority were both centralized in Jerusalem and the associated pilgrimage to the Temple in Jerusalem, which provided at least an ideological buttress for the entrenched power structures (the political and ideological role of Israelite pilgrimage is touched on in more detail below).

The third development in neo-structuralism relates to human agency. French structuralism places a strong emphasis on the unconscious underlying structures which shape cultural creation and practice. This is often understood as leaving little or no room for human agency. While neo-structuralism maintains a strong emphasis on unconscious underlying structure, it also argues that through the mediation of practice, that is, the ongoing instantiation of structure in ethnographically contextual usage, individuals can shape, at a conscious level, aspects of underlying structure. This shaping is not through the conscious manipulation of structural elements or equations, but through the selective emphasis or de-emphasis on aspects of structure. This process is facilitated via the complex cultural objects created via bricolage; a process which can use material from varying cultural sources and thus provides opportunities for selective emphasis based on contextual identity, self perception or ideology. The nature of the objects created by the bricoleur can also facilitate movement, arising from acceptance or rejection of particular elements, in a strongly marked direction - thus the rejection of any 
cultural practices that seem to include non-Israelite elements can lead to a more strongly oppositional structure, whereas an acceptance of non-Israelite elements may move the structure to a more mediated position - these two processes may be characteristic of the transformation in structure found in rabbinic and Christian material. The rabbinic material is perhaps even more strongly oppositional than the Biblical, while the Christian material is based on a much stronger positive balanced view of mediation.

The location of the mechanism for transformation in individuals or groups of individuals is important in relation to the understanding both of transformation and underlying structure. Some discussions seem to place underlying structure solely within the mind as a process of thinking or thinking about thinking. Neo-structuralism suggests that structures come into play in practice - that is through the interrelationship between thought and action. The processes of transformation must also be sought in practice rather than thought; practice provides a forum for the interplay between the individual or the group and the abstract underlying structure - it is the particularity that arises in practice, its choices, variation and improvisation, that allows ultimately for the transformation of the abstract cultural generality of underlying structure.

\section{Modeling Biblical Sacred Place}

While the biblical text contains minimally two variations on its primary model of sacred place, that is, the dynamic version, the Mishkan, developed in Exodus (and further refined in Leviticus and Numbers) and the static version, the Temple of Solomon described in 1 Kings, both of these models are based on a common abstract model. ${ }^{2}$ Arguably, the model presented in

\footnotetext{
${ }^{2}$ It has been suggested that two forms of dynamic sacred space are developed in Exodus - a simple form and the more complex form discussed here (see for example Haran, M. [1960] "Ohel Moedh" in Pentateuchal Sources in Journal of Semitic Studies, 5(1), 50-65). The simple form, derived from Exodus 33:7, Numbers 12:4 and Deuteronomy 31:14 and other related sources, is comprised solely of the Tent of Meeting, which is placed outside of the camp rather than at its centre. These discussions suggest both a conscious and unconscious structure that is different from the "authoritative" model. On the conscious level these arguments suggest that there was a different model of piety, historically prior to that found in the more complex model, that is, a prophetic model based on individual rather than communal piety. On the unconscious model, placement of the Tent of Meeting outside the camp suggests a very different relationship between Israel and the divine. Like the authoritative model it remains oppositional - with the divine set in clear opposition to Israel (with the camp representing
} 
Exodus is in itself an abstraction, that is, a fictionalized version developed during the Babylonian Exile that was based on the Temple in Jerusalem. As the dynamic model contains most of the key features we will therefore use it as the basis of our discussion. ${ }^{3}$ The discussion will also examine the implications of the dynamic model in relation to those of the static model.

Dynamic biblical sacred place was minimally divided into four zones: the החדש קדשים, החצר, the Holy of Holies; the Court (in a more detailed division the court could be subdivided in to zones of increasing holiness); and the Camp. ${ }^{4}$ These sacred places are illustrated in Figure $1 .{ }^{5}$ Based on the placement of entrances, movement into increasingly sacred space was always in a westward direction. The different zones are defined and distinguished in at least three significant ways: human presence, divine presence and purity. The human and divine aspects are opposites. As one moves in a westward direction the range of people allowed to enter the sacred precinct is narrowed; all Israel (which is a pure state) are permitted within the camp; only the Levites, one of the twelve tribes, are permitted in the Court; only the Cohanim (the Priests), a subset of the Levites are permitted in the Holy; and, only the High Priest is permitted in the Holy of Holies. An interesting feature of this process of narrowing is that it is always done, with perhaps the exception of the High Priest, on an intrinsic basis: Israel is defined on an intrinsic basis in relation to the nations, that is, descended from Jacob's twelve sons; the Levites are defined as being

\footnotetext{
Israel) - but there is no possibility of recapitulating oppositions. The divine is equally set in opposition to all humanity with Israel being one of a larger set. There seems little necessary reason to give historical precedence to the prophetic model. It seems likely that Haran's arguments are based on a modern preference for individual piety and thus seek to give it greater validity by seeing it as historically earlier and the source critical preference for the prophetic mode over that of the priests. Nonetheless, the model suggested by Haran and others may reflect one of the competing structural models that are suggested both theoretically and ethnographically by this article.

${ }^{3}$ One of the most complete descriptions of the dynamic version of sacred space is found in Exodus 25-27. That text is followed by the associated consecration of Aaron and his sons as the Cohanim or Priests. The Biblical descriptions of Solomon's Temple, that is the static centralized model, are most fully developed in 1 Kings 5-9 and 2 Chronicles 3-5.

${ }^{4}$ Haran $(1978,184)$ suggests that the sacred spaces could be further subdivided into more complex zones of increasing sanctity. The process of further subdivision does not pose a problem for the models discussed below as it does not suggest areas of overlap; each zone was still clearly demarcated. It is likely that if Haran is correct there were similarly different individuals who were allowed access to these particular zones.

${ }^{5}$ The abstract model depicted in Figure 1 is based on that found in Jenson $(1992,90)$.
} 
descended from Levi (one of the twelve sons); and, the Cohanim are defined as being descended from Aaron (descended from one of the Levitical families). This intrinsic basis of definition is discussed further below. The divine aspect moves in the opposite direction. The divine is most present in the Holy of Holies and least present in the Camp. The purity as a symbolic marker works in a related way to both the human and the divine - on the one hand the highest degree of purity is associated with the divine and thus with the Holy of Holies and the weakest degree with Israel and thus the Camp. Access of people to locations of increasing sanctity is thereby also defined by purity: only those individuals who have the highest degree of purity are allowed to enter the Holy and the Holy of Holies. The intrinsic definition reflects this - presenting both a winnowing and narrowing down that is similar to the winnowing and narrowing down presented in the early chapters of Genesis as a means of differentiating and defining the line of Abraham in relation to the rest of humanity.

On the surface there seems to be a relatively simple way of modeling these four zones and the related aspects of access, divine presence and purity. A concentric model, depicted in Figure 2, brings together all the elements. It illustrates the narrowing process, with the model ultimately focused on the centre point, the Ark of the Covenant in Holy of Holies that also represents the divine. The concentric model also suggests the need for at least one additional zone, the world, which is the larger relatively impure zone in which the Camp and the other zones are located. A variation on this type of concentric model is found in Milgrom's discussion of purity and food rules in his commentary on Leviticus (see Figure 3) ${ }^{6}$ His use of the concentric model highlights the problematic implications of that model. His analysis suggests that the concentric model allows for movement between the different zones. Israel can become a kingdom of priests, and thus presumably enter the Holy and the nations can become Israel and thus move into the Camp. The concentric model implies a relative difference between the different levels, including that between the Camp and the World.

\footnotetext{
${ }^{6}$ Milgrom presents an extensive discussion of this issue in his commentary on Leviticus 11 and 19 (1991, 718-736 and 2000, 1718).
} 
At least two of the symbolic markers, however, suggest problems with this concentric model. As indicated above in relation to human access to sacred place, access is determined on the basis of an intrinsic rather than a relative distinction. The definition of each of the categories is determined by birth, it is therefore fixed and unbridgeable - the nations (in principle) cannot become Israel, Israel cannot become Levites and Levites cannot become Cohanim. On this basis, movement into the centre of the circle is impossible and structurally illogical.

Purity, particularly in respect of the relationship between the Camp and the World creates a similar boundary - the Camp is defined as pure and the world as impure. The category of טהורה, purity, can be seen as defining the range of sacred place and creating, as suggested, an intrinsic boundary between the Camp and the World. The need for purity and thus the extension of sacred place ends with the boundary of the Camp. The opposing term טמה, impure, defines those things that must be excluded from the Camp, for example, the leper in Leviticus 13:45. The world is therefore outside of sacred space and defined by the term impure. The Camp and the World are seen as distinct and unbridgeable categories - there is no mediating category between the two. The two categories, like the definition of the different groupings within humanity are intrinsic rather than relative. The categories of pure and impure and the intrinsic definitions of human beings suggest an oppositional model between the Camp and the World rather than a concentric one.

Structuralist theory suggests that underlying structure is relatively parsimonious, that is, the same structure rather than different structures will be recapitulated at different levels within the same system. If one level was characterized by one structure and other levels by different structures that were not irreducible, then this would create insurmountable logical conflicts. For example if one level allowed mediation or movement and another did not the system would be characterized simultaneously by two inconsistent and contradictory equations. Thus, the oppositional aspect of the relation between the Camp and the World (and in relation to people 
between Israel and the nations) defined by the elements pure and impure suggests that the relations between the other levels in the system should be structured in an identical way.

The intrinsic elements that define the Cohanim, Levites and Israelites respectively suggest that they too should best be understood via an oppositional rather than a concentric model. In respect of people, at the widest level Israel is set in structural opposition to the nations; each is related to a particular place. The Israelites are associated with the widest level of sacred place, that is, the Camp (or the Land of Israel) and the nations are associated with the impure world. On the next level, within the broader category of Israel, the Levites are set in opposition to the Israelites - an intrinsic unbridgeable opposition. The Levites are associated with the Court of the Tabernacle (or the Temple) and the Israelites with the Camp. The next level, within the category of Levites, is the opposition between the Cohanim and the Levites. The Cohanim are associate with the Holy and the Levites with the Court. Finally, within the category of Cohanim, the High Priest is set in opposition to the Cohanim. There is an associated opposition between the Holy of Holies and the Holy. This model is illustrated in Figure 4. The key to the system is that the operative opposition is based on the initial variable chosen, for example, so that if the Levites are the initial variable then the Israelites or the Cohanim will be the other variable; within this system the Levites would not be set in opposition to the nations.

This model allows us to address one of the issues that underlies Milgrom's transformational concentric model, the possibility suggested in Exodus 19:6 that Israel could become a ממלכת כוהנים, that is, a "Kingdom of Priests". Based on the oppositional model here, this does not indicate that Israel would become Cohanim, specifically defined as being descended from Aaron, rather it suggests that in relation to the nations Israel stands in the structural position of priests. There is no transformation or movement implied in the text, rather due to the variable nations the appropriate oppositional variable is that of Israel. 
The logic of this recapitulating system is illustrated in the following equation.

$$
\mathrm{A}(\mathrm{x}): \mathrm{B}(\mathrm{y}) \approx \mathrm{B}(\mathrm{x}): \mathrm{y}(\mathrm{A}-)
$$

The equation in this context represents the recapitulating aspect of the system. The elements in the first half of the equation represents the internal relations, that is within Israel, and the elements of the second half represent the external relations, that is, between Israel and the nations. In the first half God will be used as a marker for the marked elements of Israelite structure, that is, the Priests and the Levites represented by variable A. This variable is defined by qualities of sacredness and purity indicated by $\mathrm{x}$. This is set in opposition to Israel, that is the people as a whole, variable B which is defined in opposition to A as impure and outside (in a spatial and genealogical sense). In the second half of the equation, the recapitulated external model, variable $B$ is place on the privileged side of the equation, it is defined by the terms used in the first half for variable A. This, however, does not suggest transformation, but rather that in opposition to a new variable $\mathrm{x}$, B needs to be redefined (it would retain its original definition in relation to $A$ ). In the external model $x$ represents the oppositional category, that is, the nations, and provides a definition of that category, that is, $x=$ profane and outside which is further defined by A inverted, that is, "not god" or non-sacred.

The consistency of the underlying structure bringing together place and social structure, and on the surface using place to validate and support social hierarchies suggests that this authoritative model is closely associated with the power elites of exilic and post exilic Israel and their ideologies. This is further strengthened by the identity of the underlying structures identified here and those found in respect of narrative myth and food rules (Kunin 2004). This is not, however, to suggest that underlying structure is merely an artifact of ideology. Neo-structuralism argues that while the underlying structure is unconscious and thus not amenable to conscious manipulation, within all social formations there will be variants, based on 
differential privileging or emphasis that are associated with different interest or class groupings within society. In different contexts, both diachronic and synchronic, the models used by different groups may become more or less dominant. Thus the dominance of the authoritative model and the apparent pervasiveness of its variant on Israelite structure is due to its contextual dominance at the time the texts in question were edited or redacted.

As we have already noted in respect of the simple and complex model of the Mishkan, the biblical text includes alternative variants on Israelite structure. Haran's model, cited above, provides insight into the underlying structural complexity. If his analysis is correct, there appears to be a significantly different take on structure to that found in the authoritative model. His analysis suggests that the Tent of Meeting was placed outside of the camp rather than at its centre. Although his discussion focuses on the conscious theological implications of this difference, that is a prophetic, individualized religion as opposed to a priestly communal form, there are clear implications in respect of structure. Placement of the Tent in the centre of the camp is closely associated with the recapitulating model discussed above, ultimately creating a logic whereby the community of Israel is set in structural opposition to the nations with a clear and unbridgeable boundary. The nature of each category is intrinsic and the nations are structurally and genetically defined as outside. The alternative model suggested by Haran denies the aspect of recapitulation; it places the divine, symbolized by the Tent in one category and the camp - minimally symbolizing Israel and maximally symbolizing all humanity is in the oppositional category. On the strength of this model there is no basis for logical distinctions within Israel or humanity, nor is there a basis for a priesthood or Israel as a kingdom of priests in relation to the nations. In theological terms Haran associates this with the prophetic model of individual relation, which is open to either all Israel or all humanity equally.

Although there appear to be significant structural differences between the simple and complex models, these differences are related to emphasis rather than significant structural transformation. The basis of the complex model 
is structural opposition with little or no mediation. Thus the categories are defined as intrinsically distinct and the boundaries are unbridgeable. The recapitulating aspect is an extension of structure to higher levels - but is not a structurally necessary extension. The simple model is based on an identical underlying structural equation, that is, an oppositional model with little or no mediation. In this case the two categories, the divine and humanity, are also intrinsically different; the opposition, however, starts and ends in relation to the variables humanity and God, thus removing any possibility of recapitulation. Both variants of the structure are closely related and could be seen as arising from the same cultural matrix. This analysis, however, does imply that Haran's suggestion that the simple model has necessary diachronic priority over the complex may not be supportable, as both could represent competing synchronic variants on underlying structure.

It might be suggested that Milgrom's concentric model may also represent a competing structural model. As indicated in the discussion above, however, Milgrom's model is based on an underlying structural equation that is significantly different from that of the authoritative model. Milgrom's model allows for movement between categories - Israel can become priests and the nations can become, in effect, Israel. Thus the structure is a weakly oppositional model, with positive mediation, that is, his model implies potential overlap and movement between categories. The authoritative model (as well as the simple model) is described by the following equation, A-B (-m). Milgrom's model is described by the equation AnB $(+m){ }^{7}$ The difference between these equations is not one of emphasis or quantity, but rather one of quality. It is perhaps significant that Milgrom's model is similar to that found in the New Testament and underlies much of current Biblical interpretation and the classic approaches to both Old Testament and New Testament texts.

The Biblical texts include an additional variant competing model of sacred place, that is, the multiple model as opposed to the singular model

\footnotetext{
${ }^{7}$ In these equations A and B are the variables, for example Israel and the nations. The ' - ' and ' $n$ ' describe the relation between the variables, that is, negative and neutral respectively. The $'-m$ ' and ' $+m$ ' refer to the nature of mediation allowed by the system, that is negative and positive respectively.
} 
intrinsic to the authoritative approach. The authoritative model makes a strong claim to singularity. Within the dynamic model presented in Exodus through Deuteronomy the singularity is unquestioned - sacred place is defined by the Camp, which is also the definition of Israel (the people) and has the Tent of Meeting and the Ark of the Covenant at its centre. There is no suggestion in the text of there being alternative models, that is, separate camps defined in the same way. The singularity of the dynamic model is seen as a validation of that of the static model, with the Temple, ultimately in Jerusalem, seen as replacing the Tent of Meeting and housing the Ark.

The singularity and focus of the authoritative model ultimately on Jerusalem is associated with political and hierarchical authority as well as communal identity. The role of the Tent and Camp in defining the people has already been highlighted. The Temple, particularly as a centre of pilgrimage must be seen in a similar way. God's Place in the World (Kunin 1998, 64-91) demonstrated the problems associated with the application of Victor Turner's (Turner \& Turner 1978) analysis of pilgrimage in relation to the Israelite material. The analysis suggested that the Israelite pilgrimage to the centre rather than the periphery served as a means of strengthening and validating Israelite identity in opposition to the nations. This identity was political and religious as both had their centers in Jerusalem. There was also clearly a strong economic basis for pilgrimage to Jerusalem as witnessed by the New Testament, that is, the money changers housed in the Temple precincts. The Biblical text, 1 Kings 12:25-33, also includes a clear recognition of the political role of pilgrimage to Jerusalem - and indeed it is the political aspect rather than the religious that provides the basis for Jereboam's establishment of two alternative pilgrimage sites, that is Dan and Beth El.

As indicated in the text from 1 Kings, the Biblical text also includes a multiple or non-centralized model of sacred place. Throughout much of the text sites alternative to Jerusalem are defined as sacred places. Thus, for example, Beth El, the site chosen by Jereboam, is validated as a sacred place in Genesis 28:10-22 and 35:1-14. In both cases they are validated via Jacob who is seen as being the ancestor of all of the Israelite tribes. Other sites 
are associated with the other patriarchs or with other significant figures; for example, in 1 Kings 18:20-40 Mount Carmel is particularly associated with Elijah (who rebuilt the altar there). The text also depicts various attempts by the center to remove these alternative sacred places; this is specifically illustrated in 2 Kings 23.

The multiple model presents a very different profile than do the models discussed above. If, however, its use of variables is examined, its relation to the authoritative model can be clarified. The particular variable upon which the authoritative model focuses is important in understanding how it works. The model is particularly concerned with the widest level of opposition, that is, between Israel and the nations. At this level Israel is defined as a unitary, singular entity in opposition to the nations, which are in this context also a singular entity. This focus leads to a recapitulating singular model of structure down to the lowest level of the High Priest and the singular Ark of the Covenant (and arguably a singular notion of the divine). A similar pattern is evident in genealogies in Genesis. Two forms of genealogies are developed a segmentary miltilinear form and a unilinear form. The unilinear form is used to develop and validate the qualitative difference between Israel (the people) and the other nations.

The nature of the holiness of the places in the multiple decentralized model seems to be a different kind than in the other models - it is at least potentially intrinsic rather than situational or contextual. It appears, at least from the Genesis texts relating to Beth $\mathrm{El}$, that while the revelational act is significant in identifying the site as holy it does not cause the site to be holy. Jacob states of Beth El, "this is a holy place, yet I knew it not" (1 Kings 12). Beth El is holy prior to the revelations; it is the intrinsic holiness that seems to allow the revelations to occur. This intrinsic element is also indicated in those sites whose holiness is related to geographic location, that is, groves and high places. The holiness seems to be intrinsically related to the type of location rather than any contextual use. The intrinsic nature of holiness is structurally significant in relation to the Israelite structural understanding of transformation, that is, the strongly negative view implicit in a model based 
on the equation A-B (-m). If a fixed site could be transformed from profane to holy, then the logic would suggest that other spaces or cultural objects could make the same move. The intrinsic nature of these sites' holiness denies that cultural/structural possibility.

The variables used in the multiple decentralized model, however, have a different focus. It is not related to the nations, but rather to other elements within Israel. This is particularly seen in the text cited above from 1 Kings 12. On a structural level it is likely that these multiple sites were used to validate localized identities - and were often centered on localized version of Israel's god. Thus, given the non-unitary focus the underlying structure in the multiple decentralized model, the same structural equation could lead to a very different model of society. This issue can be further clarified by recourse to the segmentary opposition model. From the outside, a society based on segmentary opposition would (or could) appear to be singular and unified, based on what it is defining itself against. From the inside, without that level of opposition, the defining units would appear to be highly segmented, multiple and decentralised.

The analysis presented above illustrates the wide range of variation (while not exhausting all possible variations) that can arise from a single underlying structural equation. Each of the three variants, and in spite of calling one authoritative we would not want to consider any particular form (or indeed any possible form) as the "pure" Israelite form, leads to different cultural possibilities based on either the level or variable chosen or the particular aspect emphasized. The variation in level or emphasis provides possibilities for ongoing transformation, as each of the variants can itself lead to further variations. It is possible, for example, that the simple variant ultimately developed into the New Testament form of mediated underlying structure.

The variation analyzed here is essentially within the framework of a self-defined community - that is Israel via that mediation of texts edited or redacted in the exilic/post exilic periods. As suggested, it highlights the cultural possibilities for transformation and or variation within a 
"cultural" matrix. In a sense, the biblical text creates an artificial notion of Israelite culture that colludes with the anthropologists' creation of culture. Nonetheless, the discussion has touched on aspects that may relate to the fuzzy boundaries suggested by the theory. The multiple model reflects a wide range of cultural interaction, certainly with earlier religious forms, and most likely with contemporary religious forms distinct from the authoritative model. This is reflected in the differential origin and nature of the different sites - some being associated with a figure who may have been part of other traditions, some including geographic locations whose sanctity was shared with neighboring communities. It is possible that these overlapping "cultural" forms led to differential emphasis within the structure through the merging or conflict between structures belonging to neighboring communities. On an historical level we can see the fuzzy nature of cultural boundaries in a different way, particularly via the process of Hellenization. It is important to note that structural conflict and opposition of structural forms (that is 0 transformation) is also a form of transformation.

In the theoretical discussion the issue of agency was suggested as one key development in neo-structuralist theory. While, given the historical distance from the Biblical period, it is impossible to ethnographically demonstrate agency, it is possible to indicate its work indirectly. If we examine the structural models of sacred place in biblical and rabbinic forms, we find a clear transformation from the authoritative static centralized forms to the dynamic multiple decentralized form, which is different from any of the biblical variations. Although the rabbinic form shares a common structure with the earlier variations, it has a new emphasis, based on a non-hierarchical and virtually singular depiction of the community in relation to the other nations. While this transformation is a communal level, the role of individual agency must have been significant in moving to the new model. Culture does not have a supra-individual existence; it exists via the individuals that make it up, and is transformed through the action of individuals and through groups of individuals who choose to act in concert. The variations in structure that arise through the complexity 
of communities, and through the fuzzy boundaries of different cultural communities provides the bases from which transformation can occur, it does not cause, effect, or direct the process.

One of the aspects raised in the above discussion is the issue of dynamic sacred place and its implications for Israelite and later rabbinic models of sacred place. The dynamic form of sacred place suggests that the particular location is not the defining element. By definition, dynamic sacred place moves from place to place. It is determined by the presence of the Camp, and perhaps more specifically the Camp centered on the Tent of Meeting and the Ark. The dynamic aspect suggests a close association between people and place. It also suggests the importance of cultic practices which are also determinative of sanctity.

This dynamic aspect and non-intrinsic aspect of sacred place is different from that found in the multiple version of sacred place. In the discussion of the sanctity of particular places there are either events or geographic features that determine the sanctity of the location. Thus, many sacred places, like Beth El discussed above, are defined by experiences of the divine - this leads them to be seen as intrinsically holy. Other places gain their holiness through particular geographic features, for example, high places or groves of trees. In both cases many of these sites were pre-Israelite holy places as well.

Although the static form of centralized sacred place has aspects of both the non-intrinsic and the intrinsic, in many respects it is closer to the non-intrinsic form. While the Temple was ultimately built in Jerusalem, 1 Samuel indicates that it had been in other locations, including at least Shiloh, prior to its final location. The description of Shiloh in the text does not suggest any revelational or geographic significance to the location - it might be merely seen as a political and religious center for the community forming a similar role, albeit static, to the Tent of Meeting in the Center of the Camp. As indicated, the final location for the Temple was Jerusalem. Interestingly, Jerusalem is not identified in the text with any significant revelatory experience, nor is it identified as a High Place, that is, a Canaanite site of worship (though it is likely that it served that purpose). The text 
suggests that the Temple was built by Solomon to house the Ark and to bring together political and religious authority. While, as Levenson points out, prophetic texts emphasise the significance of Jerusalem in terms of centrality and perhaps as axis mundi, he does not convincingly demonstrate that this role is understood as intrinsic; it could equally be based on the fact that the Temple was built there rather than it being the cause of the Temple being built in Jerusalem (Levenson 1985, 115-125). ${ }^{8}$ It is only in rabbinic sources that Jerusalem, or more specifically the site of the Temple, is more strongly associated with a particular revelational event, the sacrifice of Isaac, and thus given an intrinsic rather than contextual quality.

This non-intrinsic definition is carried over during the rabbinic period into the definition of the Synagogue. The synagogue, as a building, has only minimal sanctity. This is seen in the fact that after its use as a synagogue it can be transferred to almost any purpose. This is seen in the Mishnah, Megillah 3:2, which states that a synagogue cannot be sold to be used as a bathhouse, tannery, immersion pool, or urinal - all uses that would reflect badly on the honour of the building and community, but not on its holiness. Interestingly the synagogue also takes on many of the symbols found in the Temple. The key difference between the Temple and the synagogue is that the Temple was necessarily singular, based on the singular presence of the Ark of the Covenant while the synagogue is by definition multiple, centered on an Ark, but one containing the Torah, the scrolls of God's words.

This article has had two interrelated agendas, one theoretical and the other ethnographic. The paper sought to highlight aspects of neo-structuralist theory, particularly in relation to the role and presence of structural multiplicity within a "cultural" framework. It suggested that this multiplicity should be found on two interrelated levels: the complexity found within a community that arises on the basis, for example, of different economic or interest groups and that found due to the fuzzy nature of cultural boundaries. The difference between these forms of variation is important. Intra-cultural

\footnotetext{
${ }^{8}$ This contention, that is, that the significance of Jerusalem was contextual is supported by Talmon (1976, 1630-1677), who suggests that the significance was related to Jerusalem's centrality as political rather than either geographical or spiritual.
} 
variation would be essentially one of emphasis, with a common structure shared by the different groupings. Inter-cultural variation would often be more significant, with alternative underlying structural forms coming into conflict or relation. These elements provide the synchronic materials that can be the basis of structural transformation. The article also highlighted the theoretical importance of agency as the motor of transformation that works with the variations in structure to transform underlying structure diachronically in significant or less significant ways diachronically.

The ethnographic element of the analysis examined the forms of modelling sacred place in relation to this theoretical model. The heart of the discussion presented some of the different significant models of sacred place found in the Biblical text. Three main models were presented, the monolithic centralized model (with both dynamic and static forms), the simple model and the multiple model. While each of these models had a different outcome in terms of practice, communal structure, and social hierarchy, the analysis demonstrated that they were based on the same underlying structural equation. Based on this analysis it also indicated why Milgrom's concentric transformative model was not a viable understanding of Biblical material (though it might be appropriate in relation to a Christian, academic analysis of that material). The multiplicity of models in the text also allows us to challenge the authoritative model. The multiplicity suggests that the Biblical text is, unsurprisingly, attempting to impose a particular ideological form, and to thus deny the existence of alternatives or variations on that form. In spite of this ideological function, the text reveals that sacred place and more significantly aspects of structure are significant for conflict and that this conflict is a significant motor for cultural transformation. The discussion also touched on the other aspect of structural multiplicity, that is, the fuzzy nature of cultural boundaries - due, however, to the focus on the Biblical text, ethnographic evidence of this process is only indirectly available. In a similar way, the role of agency could only be indicated indirectly. 


\section{Bibliography}

\section{Eade, J \& M. Sallnow (eds)}

1990 Contesting the Sacred: The Anthropology of Christian Pilgrimage. London: Routledge.

\section{Friedland, R. \& R. D. Hecht}

1991 The Politics of Sacred Place: Jerusalem's Temple Mount/al-haram alsharif. - Jamie Scott \& Paul Simpson-Housley (eds), Sacred Places and Profane Spaces, 21-61. Westport: Greenwood Press.

\section{Haran, M.}

1960 "Ohel Moedh" in Pentateuchal Sources. - Journal of Semitic Studies, $5(1), 50-65$.

1978 Temples and Temple-Services in Ancient Israel: an Inquiry into the Character of Cult Phenomena and the Historical Setting of the Priestly School. Oxford: Clarendon.

Jenson, P. P.

1992 Graded Holiness. Sheffield: Sheffield Academic Press.

\section{Kunin, Seth D.}

1998 God's Place in the World. London: Continuum.

2004 We Think What We Eat. London: T \& T Clark.

\section{Lefebvre, Henri}

1991 The Production of Space. Oxford: Blackwell.

\section{Levenson, Jon D.}

1985 Sinai and Zion: An Entry into the Jewish Bible. Minneapolis: Winston Press.

\section{Milgrom, J.}

1991 Leviticus 1-16 (The Anchor Bible). New York: Doubleday.

2000 Leviticus 17-22 (The Anchor Bible). New York: Doubleday.

\section{Sheldrake, $\mathbf{P}$.}

2001 Spaces for the Sacred. London: SCM Press.

\section{Talmon, Sh.}

1976 177- Tabriz 45, 163. - "והשיטה המשווה ”טבור הארץ

\section{Turner, Victor \& Edith Turner}

1978 Image and Pilgrimage in Christian Culture. New York: Columbia University Press. 


\section{Appendix: Figures}

\section{Figure 1}

1

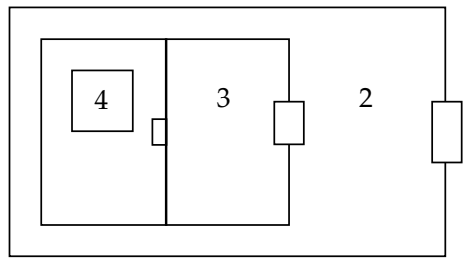

1 The Camp

2 The Court

3 The Holy

4 The Holy of Holies

Figure 2

Figure 3

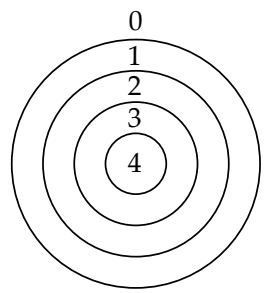

0 The World/Nations

1 The Camp/Israel

2 The Court/Levites

3 The Holy/Cohanim

4 The Holy of Holies/High Priest

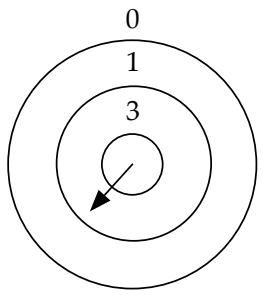

0 Earth (Mankind)

1 Land (Israel)

3 Sanctuary (Priests)

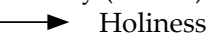

Figure 4

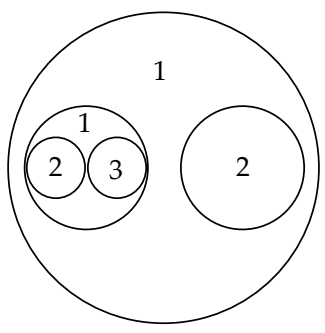

0 The World/Nations

1 The Camp/Israel

2 The Court/Levites

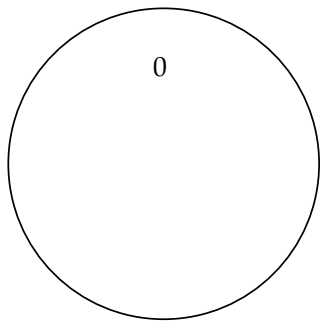

3 The Holy/Cohanim

4 The Holy of Holies/High Priest (not included in diagram) 